\title{
Prevalence of hypertension and associated cardiovascular risk factors in an urban slum in Nairobi, Kenya: A population-based survey
}

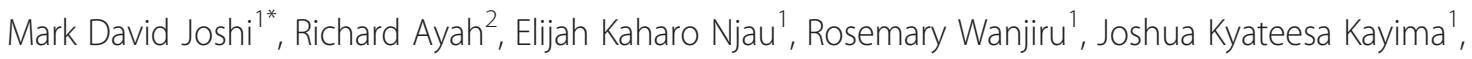
Erastus Kennedy Njeru ${ }^{2}$ and Kenneth Kipyegon Mutai ${ }^{3}$

\begin{abstract}
Background: Urbanisation has been described as a key driver of the evolving non-communicable disease (NCD) epidemic. In Africa, hypertension is the commonest cardiovascular problem. We determined the prevalence and risk factor correlates of hypertension in the largest Nairobi slum.

Methods: In 2010 we conducted a population-based household survey in Kibera, a large informal settlement in Nairobi City; utilising cluster sampling with probability proportional to size. Households were selected using a random walk method. The WHO instrument for stepwise surveillance (STEPS) of chronic disease risk factors was administered by trained medical assistants, who also recorded blood pressure (BP) and anthropometric measures. BP was recorded using a mercury sphygmomanometer utilising the American Heart Association guidelines. Hypertension was defined as per the 7th Report of the Joint National Committee or use of prescribed antihypertensive medication. Those with hypertension or with random capillary blood sugar (RCBS) $>11.1 \mathrm{mmol} / \mathrm{l}$ had an 8 hours fasting venous blood sugar sample drawn. Age standardised prevalence was computed and multivariate analysis to assess associations.
\end{abstract}

Results: We screened 2200 and enrolled 2061 adults; 50.9\% were males; mean age was 33.4 years and 87\% had primary level education. The age-standardised prevalence of hypertension (95\% Cl) was 22.8\% (20.7, 24.9). 20\% (53/258) were aware of their hypertensive status; $59.3 \%$ had pre-hypertension; $80 \%$ reported high levels of physical activity and 52\% were classified as harmful alcohol drinkers; $10 \%$ were current smokers and $5 \%$ had diabetes. Majority of males had normal BMI and waist circumference, whereas a third of females were obese or overweight and $40 \%$ had central obesity. Older age, higher general and central obesity were independently associated with hypertension and higher SBP and DBP readings.

Conclusions: Our findings of high prevalence of hypertension, in association with excess body weight in this poor urban slum community, point to the need for greater awareness and implementation of primary preventive strategies.

Keywords: Hypertension prevalence, Urban health, Poverty areas, Africa South of the Sahara, Non-communicable diseases

\footnotetext{
* Correspondence: joshingetich@gmail.com

'Department of Clinical Medicine and Therapeutics, School of Medicine, College of Health Sciences, University of Nairobi, P.O. BOX 19676-00202, KNH, Nairobi, Kenya

Full list of author information is available at the end of the article
} 


\section{Background}

The prevalence of Non-Communicable Diseases (NCD) in low- and middle-income countries is rising rapidly [1]. Half of the current health burden in developing nations is attributable to non-communicable diseases [2]. By 2020 it is projected that non-communicable diseases including, hypertension, will outstrip communicable diseases as the leading cause of death. Demographic changes, increasing urbanization and lifestyle changes are some of the factors contributing to the increasing burden of NCD [3].

Hypertension is a major contributor to NCD burden in both developed and developing countries [4]. Hypertension is a primary cause of haemorrhagic and atherothrombotic stroke, hypertensive heart disease, hypertensive kidney failure, coronary artery disease [5,6].

Hypertension is now the most common cardiovascular problem in Africa, and it is estimated that more than 20 million people are affected [7]. In sub-Saharan Africa hypertensive end organ damage is a major source of morbidity and mortality [6]. The reported prevalence of hypertension in Africa ranges from $25 \%$ to $35 \%$ in adults aged 25 to 64 years [7], and increases with advancing age. A recent study of urban and rural Tanzania reported rates of stroke mortality higher than those of England and Wales, and suggested that untreated hypertension is an important etiological risk factor [8]. In Kenya there is a paucity of data on hypertension prevalence, and at the time of our survey in 2010 only two studies had been reported. The initial 1986 survey was undertaken in a regional centre, among both rural and urban residents, reported nonstandardised hypertension prevalence of 6.4\% [9]. A 2008 regional cross-sectional study, restricted to subjects aged over $50 \mathrm{yr}$ and conducted in predominantly rural population, reported a prevalence of 50.1\% [10].

Urbanisation is a key driver of the evolving NCD epidemic in developing countries [3]. In Kenya 22.3\% of the population is urban, with an urban population growth rate of $4.2 \%$ almost double the national population growth rate of $2.4 \%$ [11]. In the capital city Nairobi, a majority $(60 \%)$ of the population live in slums with much of the migrant population settling in slums. Furthermore $75 \%$ of the urban population growth is absorbed by informal settlements. To address the data void on the burden of hypertension in Kenya, we report on the prevalence and risk factor correlates of hypertension, in a representative sample of the rapidly expanding urban poor segment of our population.

\section{Methods}

The urban slum of Kibera in Nairobi, the capital of Kenya was chosen as the study area. Kibera is located $5 \mathrm{~km}$ southwest of Nairobi city centre and is approximately 2.5 square kilometres, with an estimated 300,000 inhabitants [11]. This study was conducted using UN recommendation for cluster sampling with probability proportional to size adjusted to achieve our sample size [12]. A design effect of 2.0 was used to account for the clustering of the study participants. A sampling frame with the list of villages and the projected populations of each was obtained. As a result a total of 80 clusters each containing 10 households and thus 25 participants per cluster were created within the eight villages with the number of clusters proportional to the population size within the particular village. The households in each cluster were visited in a random walk method from the nearest health centre, church or school as the focal point in each cluster. Within each household, all consenting adults of 18 years and above, who had been residents of the area for more than 3 months, were enrolled. Exclusions included those under the age of 18 years; nonconsenting individual and pregnant women. The next household was taken as the one nearest to that previously visited until the sample size for the given cluster was achieved. The WHO STEPS-wise approach for collecting surveillance data for non-communicable diseases (NCD's) was adopted to collect data. The WHO STEP-wise approach to surveillance of non-communicable diseases is a validated instrument developed by WHO for collection of surveillance data on NCD's in resource poor settings. It is a sequential process made up of three main sections, which are the risk stratification questionnaire (step1), anthropometric measurements (step 2) and biochemical measurements (step3) [13].

The survey was conducted between June and August 2010 with research teams visiting selected household between 8 am and 4 pm daily on weekdays. We minimized missing respondents by making a maximum of two revisits on subsequent Sundays. The questionnaire was administered by study trained registered medical assistant teams supervised by a study medical doctor. The questionnaire covered the smoking habits, alcohol use and physical activity pattern, history of prior evaluation for diabetes and hypertension, and if any, the medication and lifestyle counselling that had been given. Anthropometric measures were recorded as hereunder. Height was measured to the nearest $0.5 \mathrm{~cm}$ using a metal measuring tape against a wall and a flat headboard at right angles to the wall. Weight was measured to the nearest 100 gms using a good quality bathroom scale (Ashton Meyers ${ }^{\oplus}$ ) with the subject in light clothing and without shoes. Mid upper arm circumference was measured to the nearest $0.5 \mathrm{~cm}$. Waist circumference was taken with a flexible tape measure placed on a horizontal plane at the level midpoint between the superior border of the iliac crest and the inferior margin of the last rib midaxillary plane and the recording was at the end of normal expiration. Hip circumference was measured at the widest level over the greater trochanter. Body mass index 
(BMI), (kg)/height in $\mathrm{m}^{2}$ ), was used as a measure of total body obesity while waist circumference and waist hip ratio was used as measures of abdominal obesity. Body mass index $(\mathrm{BMI})<18.5$ was recorded as underweight, 18.524.9 as normal, 25-29.9 as overweight and BMI more than 30 was recorded as obesity. Significant waist circumference was recorded as more than $102 \mathrm{~cm}$ (40 inches) for males and more than $88 \mathrm{~cm}$ (35 inches) in females. Significant waist to hip ratio was considered abnormal in females with a ratio of $>0.8$ and males $>0.9$ [14].

Blood pressure was recorded using a mercury sphygmomanometer (Riester; Jungingen Germany) after the risk factor questionnaire had been filled to ensure that subjects had been seated for at least fifteen minutes. American Heart Association guidelines for measuring blood pressure were used [15]. Three intermittent brachial cuff readings were taken and an average obtained. A random capillary blood sugar (RCBS) was recorded using a glucometer. Participants who had a RCBS $>11.1 \mathrm{mmol} / \mathrm{l}$ and those with hypertension as per study definition were invited to present themselves to the nearest health facility at a later designated date after an minimal 8 hours overnight fast. A fasting specimen of $5 \mathrm{mls}$ blood was drawn from a peripheral vein, preferably the ante-cubital fossa for venous fasting blood sugar (FBS) analysis.

Research assistants underwent training on how to complete the STEPS questionnaire and on anthropometric and blood pressure measurements to ensure standardization. The sphygmomanometers, weighing scales and tape measures were assessed weekly by taking measurements of one person on each of the instruments to ensure they were standardized. Recommended procedures for specimen collection, preparation and storage were followed to minimize pre-analytical errors. Before analysis, all the assays were calibrated according to the manufacturer's specifications. Commercial controls used to validate the calibrations. Results were transcribed onto data sheets, which were checked by two people to minimize post analytical transcriptional errors.

Hypertension was defined and classified as per the Seventh Report of the Joint National Committee [16] on prevention, detection and treatment of high blood pressure as being systolic BP $>=140 \mathrm{mmHg}$ and/or diastolic $\mathrm{BP}>=90 \mathrm{mmHg}$ or use of prescribed antihypertensive medication. Hypertension was classified into pre-hypertension, stage 1 or 2 hypertension as per JNC VII. If the systolic and diastolic pressure readings belonged to different categories, the higher of the two readings was used to assign the blood-pressure stage. Isolated Systolic and Isolated Diastolic Hypertension was defined as per the specified BP cut-offs but with only one category elevated. Participant were diagnosed with diabetes if they had a RCBS level of $>=11.1 \mathrm{mmol} / \mathrm{l}$ and a venous FBS of $>=7.0 \mathrm{mmol} / \mathrm{l}$, or had been diagnosed with diabetes or were receiving treatment for diabetes with insulin or oral hypoglycaemic agents. As per the STEPs instrument physical activity (PA) domains and the Global Physical Activity (GPAQ) analysis guide [17], categorical PA levels was coded based on total days and duration of PA and as Total PA in metabolic equivalents of task (METs) minutes per week. Total PA was classified as follows: high as >3000 MET-minutes per week; moderate as 6003000 MET-minutes per week and low as <600 METminutes per week.

Statistical analysis was undertaken using Statistical Products and Service Solutions (SPSS for Windows Ver. 16.0 Chicago, SPSS Inc). Prevalence was age standardised utilising the new WHO World Standard population, direct standardisation method [18]. Associations between the subjects socio-demographic, clinical and laboratory characteristics were examined using chi-square test for the categorical data while for the continuous variables the Student t-test was used to determine statistical significance and Mann Whitney $U$ test used in the analysis where such continuous data is skewed.

Adjusted odds ratios (OR) for the association between hypertension and body mass indices and diabetes were computed with 95\% CIs. Binary logistic regression was used to adjust for odds of hypertension associated with $\mathrm{s}$ body mass indices and diabetes and the results expressed as OR with $95 \%$ confidence intervals (CIs). Multiple linear regression was used to analyse of predictors of elevated systolic and diastolic BP and results expressed as a beta coefficients with 95\% CI. Associations were considered significant at the conventional value of $\mathrm{p}$ value less than or equal to 0.05 .

\section{Ethical considerations}

Study approval was obtained from the Kenyatta National Hospital (KNH) Ethics and Research Committee and the Ministry of Science and Technology. Administrative permission was obtained from the Nairobi City Council and the provincial administration and Kibera community leaders and elders were informed of the study. Verbal consent from head of household and written consent from all eligible adults over the age of 18 yrs was obtained. Follow up care for clinical conditions detected was facilitated by referral to $\mathrm{KNH}$ and Mbagathi district Hospital as appropriate.

\section{Results}

We screened 2200 eligible adults from 936 households in eight villages, excluded 139 (38 pregnant women, 50 declined consent and 51 below 18 yrs. of age) and thus enrolled 2061 subjects, representing a 98\% response rate. An average of 2.4 adults per household was surveyed. At analysis complete data was available in 2045 subjects with males comprising 50.9\%. 
Respondent ages ranged from 18 to 90 yrs. with a mean age of 33.4 yrs. (SD 11.6 yrs.); $53.9 \%$ were aged $25-44$ years, $28.3 \%$ were under 25 years and $5.2 \%$ were 55 years or older. Literacy level was high with $87 \%$ having either a primary or secondary level of educational attainment.

Demographics and behavioural risk factors of the study sample are depicted in Table 1. Current cigarette smokers comprised $13.1 \%$, $84.8 \%$ of whom were daily smokers. Alcohol consumption was high with $30 \%$ reported to have ever consumed alcohol; $81 \%$ of whom consumed alcohol in the previous twelve months with a consumption frequency of $19.1 \%$ on a daily basis and $52 \%$ between 1-6 days per week; the average and largest number of drinks per sitting being four and six respectfully.

\section{Physical activity}

Study subjects demonstrated a high level of physical activity (PA) that was predominantly work and travel related. Vigorous or moderate work related activity was undertaken by $75.7 \%$ (male $78.2 \%$, female $73 \%$ ), at a median duration of $7 \mathrm{hrs}$ for 6 days per week. Walking or cycling as mode of transport was undertaken by $77.4 \%$ (male $80.3 \%$, female $74.3 \%$ ) for a median duration of one hour for 6 days per week. Vigorous work related PA was more common in males whereas moderate work related PA was more common in females. (Table 1) Physical activity data in metabolic equivalents (METS) was available for $87.9 \%$ ( $n$ 1797) of sample. The median (IQR) total physical activity (PA) in MET-minutes per week was 10800 (3840, 21120) for the entire sample and 13474 (5040, 24960) among males and 8400 (3168, 15630) among females (Table 1 ). This was indicative of a very high level of total PA in both genders; with $80.2 \%$ recording high (>3000) and $17.5 \%$ recording moderate (600 to 3000) level of total PA in METs minutes per week.

\section{Body mass index}

Mean (95\% CI) Body Mass Index (BMI) was 24.2 (23.9, 24.6) in males and $27.1(26.6,27.6)$ in females $(\mathrm{P}=$ $0.000)$. BMI increased with age in both genders. Majority of males had a normal BMI. However among females $32.2 \%$ were overweight (BMI >25\%), 26.1\% were obese and $38.5 \%$ had a normal BMI; thus $58.3 \%$ of women were either obese or over-weight. Prevalence of over-weight (BMI >25-29.9) and obesity (BMI $\geq 30$ ) were significantly higher among women $(\mathrm{P}=0.0001$ for both BMI categories). Only $5.8 \%$ of men and $3.1 \%$ of females were underweight.

\section{Waist circumference}

Mean (95\% CI) waist circumference (WC) was $81.9 \mathrm{~cm}$ $(81.3,82.6)$ in males and $86.6 \mathrm{~cm}(85.6,87.5)$ in females. WC increased with age in both sexes; however $97.4 \%$ of males had a normal WC. The prevalence (95\% CI) of WC defined central obesity (WC $>88 \mathrm{~cm}$ in females \& $>108 \mathrm{~cm}$ in males) was $41.5 \%$ in females and $2.6 \%$ in males $(\mathrm{P}=$ 0.001).

\section{Waist-hip ratio}

Mean (95\% CI) waist-hip ratio (WHR) was 0.89 (0.87, $0.92)$ in males and $0.85(0.84,0.87)$ in females. Majority of both genders had normal waist-hip ratio (WHR), however $24 \%$ of women had an elevated WHR (WHR >0.80) and the prevalence of central obesity as defined by WHR was significantly higher among females $(P=0.001)$. All measures of body mass showed a statistically significant increase with age among females $(P=0.000)$; and the same were evident among male subjects $(P=0.000)$ except for WHR that did not show a statistically significant increase with age $(P=0.269)$.

\section{Blood pressure}

The crude prevalence (95\% CI) of hypertension ( $\mathrm{BP} \geq 140$ / $90 \mathrm{mmHg}$ or taking prescribed antihypertensive medication) was $12.6 \%(11.2,14.1) ; 11.7 \%(9.7,13.6)$ in males and $13.7 \%(11.5,15.8)$ in females $(P=0.166)$. Prevalence increased with age and was significantly higher among females in the age strata of $35-44$ yrs. $(\mathrm{p}=0.008)$ and 5564 yrs $(\mathrm{P}=0.001)$ (Figure 1). The new WHO Standard population age standardised prevalence of hypertension (95\% CI) was $22.8 \%(20.7,24.9)$ in the entire sample and $23.2 \%(20.4,26.1)$ in analysis restricted to those over 35 years of age. Only 20\% (53/258) were aware of their hypertensive status and among the known and drug treated hypertensive subjects $49 \%(26 / 53)$ had controlled hypertension at time of survey $(\mathrm{BP}<=140 / 90 \mathrm{mmHg}$.).

Only $30.9 \%(631 / 2045)$ of study subjects reported ever having had a BP measured by health workers and $22.3 \%$ (141/631) having been told that their BP was elevated; 95.7\% (135/141) having been informed so in the twelve months prior to interview. Of those informed of an elevated BP in the past year 39.5\% (53/135) had been prescribed antihypertensive therapy and were on the therapy in the two weeks prior to interview. The proportions advised on non-pharmacological measures for BP control were: $40 \%$ salt restriction, $28.9 \%$ increased physical activity, $25.2 \%$ weight reduction and $17 \%$ smoking cessation. Regarding alternative therapies $17 \%$ had ever seen a traditional healer and $11.9 \%$ were on current herbal or traditional remedies for the treatment of raised BP.

The mean (95\% CI) systolic blood pressure (SBP) among males and females was $124 \mathrm{mmHg}(123.1,124.8)$ and $123.5 \mathrm{mmHg}(122.7,124.4)$ respectively. The mean (95\% CI) diastolic blood pressure (DBP) among males and females was $77.5 \mathrm{mmHg}(76.9,78.1)$ and $76.9 \mathrm{mmHg}$ (76.2, 77.5) respectively. SBP \& DBP increased with age in both sexes, with no gender differential. For both SBP 
Table 1 Demographic and behavioural risk factors across sex and hypertensive status

\begin{tabular}{|c|c|c|c|c|c|c|c|}
\hline & Overall \% (n) & Male \% (n) & Female $\%(n)$ & $P$ value $\dagger$ & Hypertensive & Normotensive & $\mathrm{P}$ value $\neq$ \\
\hline \multicolumn{8}{|l|}{ Age yrs } \\
\hline $18-24$ & $28.3(578)$ & $27.7(291)$ & $28.8(287)$ & 0.051 & & & \\
\hline $25-34$ & $31.8(651)$ & $30.1(316)$ & $33.7(335)$ & & & & \\
\hline $35-44$ & $22.1(452)$ & $22.2(233)$ & $22.0(219)$ & & & & \\
\hline $45-54$ & $12.5(256)$ & $13.7(144)$ & $11.3(112)$ & & & & \\
\hline $55-64$ & $3.8(78)$ & $4.8(50)$ & $2.8(28)$ & & & & \\
\hline $65-74$ & $1.2(25)$ & $1.4(15)$ & $1.0(10)$ & & & & \\
\hline$\geq 75$ & $0.2(5)$ & $0.1(1)$ & $0.4(4)$ & & & & \\
\hline $18-90$ & $100(2045)$ & $51.0(1050)$ & $48.4(995)$ & & & & \\
\hline Years in school, mean (SD) & $9.3(3.3)$ & $9.8(3.2)$ & $8.7(3.2)$ & 0.000 & & & \\
\hline \multicolumn{8}{|l|}{ Tobacco smoking } \\
\hline Current \% (n) & $13.1(269)$ & $22(231)$ & $3.8(38)$ & 0.000 & $17.8(46)$ & $12.5(223)$ & 0.018 \\
\hline Smoking daily \% (n) & $84.8(228)$ & $89.2(206)$ & $57.9(22)$ & 0.000 & $82.6(38)$ & $85.2(190)$ & 0.656 \\
\hline Age started yrs mean (SD) & $19.7(5.5)$ & $19.9(5.7)$ & $18.6(3.4)$ & 0.304 & $21.5(6.8)$ & $19.4(5.2)$ & 0.037 \\
\hline Age started range yrs & $10-45$ & $10-45$ & $10-24$ & - & - & - & - \\
\hline Duration years mean (SD) & $16.5(10)$ & $16.4(10.2)$ & $17.3(9.1)$ & 0.696 & $21.4(11.3)$ & $15.4(9.5)$ & 0.001 \\
\hline Pack years median (Q1-Q3) & $6(2.5-10.9)$ & $6(2.4-10.5)$ & $7.5(4.4-12.0)$ & 0.303 & $8.3(3.9-13.8)$ & $6.0(2.4-10.5)$ & 0.058 \\
\hline \multicolumn{8}{|l|}{ Alcohol consumption } \\
\hline Ever consumed & $30.1(616)$ & $43.2(454)$ & 16.3(162) & 0.000 & $33.3(86)$ & $29.7(529)$ & 0.233 \\
\hline In past 12 months & $81.0(499)$ & $89.6(407)$ & $56.8(92)$ & 0.000 & $76.7(66)$ & $81.7(432)$ & 0.281 \\
\hline In past 30 days & $76.8(383)$ & $79.1(322)$ & $66.3(61)$ & 0.009 & $75.8(50)$ & $77.1(333)$ & 0.812 \\
\hline \multicolumn{8}{|l|}{ Frequency in past 12 months } \\
\hline Daily & $19.1(95)$ & $22.1(90)$ & $5.5(5)$ & 0.008 & $25.8(17)$ & $18.1(78)$ & 0.180 \\
\hline 5-6 days/week & $14.3(71)$ & $13.8(56)$ & $16.5(15)$ & & $7.6(5)$ & $15.3(66)$ & \\
\hline 1-4 days/week & $28.7(143)$ & $27.0(110)$ & $36.3(33)$ & & $28.8(19)$ & $28.7(124)$ & \\
\hline 1-3 days/week & $23.3(116)$ & $22.9(93)$ & $25.3(23)$ & & $18.2(12)$ & $24.1(104)$ & \\
\hline $\begin{array}{l}\text { Average number of drinks median } \\
\text { (Q1-Q3) }\end{array}$ & $4(3-6)$ & $4(3-6)$ & $3(2-5)$ & 0.087 & $4(4-5)$ & $4(3-6)$ & 0.272 \\
\hline Largest number of drinks/sitting & $6(4.5-9)$ & $6(5-9)$ & $6(4-7)$ & 0.026 & $6(3-8.5)$ & $6(5-9)$ & 0.178 \\
\hline \multicolumn{8}{|l|}{ Physical Activity } \\
\hline Work Vigorous & $29.6(606)$ & $39.1(411)$ & $19.6(195)$ & 0.000 & $24.4(63)$ & $30.5(543)$ & 0.050 \\
\hline Days/week median (Q1-Q3) & $6(5-7)$ & $6(5-7)$ & $6(3-7)$ & 0.537 & $6(5-7)$ & $6(5-7)$ & 0.116 \\
\hline Hours/day median (Q1-Q3) & $8(3-9)$ & $8(4-9)$ & $6(2-8)$ & 0.000 & $8(3-9)$ & $8(4-9)$ & 0.877 \\
\hline Work moderate & $46.1(943)$ & $39.1(411)$ & $53.4(532)$ & 0.000 & $43.0(111)$ & $46.6(830)$ & 0.295 \\
\hline Days/week median (Q1-Q3) & $6(5-7)$ & $6(4-7)$ & $7(5-7)$ & 0.000 & $6(5-7)$ & $6(5-7)$ & 0.420 \\
\hline Hours/day median (Q1-Q3) & $6(3-8)$ & $6(3-8)$ & $5(2.1-8.0)$ & 0.000 & $8(3-10)$ & $6(3-8)$ & 0.016 \\
\hline Travel (walk/cycle) & $77.4(1583)$ & $80.3(843)$ & $74.3(740)$ & 0.001 & $70.2(181)$ & 78.5 (1399) & 0.003 \\
\hline Days/week median (Q1-Q3) & $6(5-7)$ & $6(5-7)$ & $6(4-7)$ & 0.001 & $6(5-7)$ & $6(5-7)$ & 0.148 \\
\hline Hours/day median (Q1-Q3) & $1(0.75-2)$ & $1.3(0.8-2.0)$ & $1(0.7-2.0)$ & 0.023 & $1.3(0.5-3)$ & $1.0(0.8-2)$ & 0.480 \\
\hline Recreational vigorous & $15.2(311)$ & $21.7(228)$ & $8.3(83)$ & 0.000 & $12.0(31)$ & $15.7(280)$ & 0.127 \\
\hline Days/week median (Q1-Q3) & $2.0(1-3)$ & $2.0(1.0-3.0)$ & $2(1-3)$ & 0.737 & $2(1-5)$ & $2(1-3)$ & 0.603 \\
\hline Hours/day median (Q1-Q3) & $2.0(0.8-2)$ & $2.0(1.0-2.0)$ & $1.4(1-2)$ & 0.142 & $1.2(0.5-2)$ & $1.5(1-2)$ & 0.165 \\
\hline Recreational moderate & $16.4(336)$ & $16.9(177)$ & $16(159)$ & 0.586 & $10.5(27)$ & $17.3(309)$ & 0.006 \\
\hline Days/week median (Q1-Q3) & $3(1-6)$ & $3.0(1.0-6.0)$ & $3(1-6)$ & 0.986 & $4(2-7)$ & $3(1-6)$ & 0.214 \\
\hline
\end{tabular}


Table 1 Demographic and behavioural risk factors across sex and hypertensive status (Continued)

\begin{tabular}{|c|c|c|c|c|c|c|c|}
\hline Hours/day median (Q1-Q3) & $1(0.7-2)$ & $1.5(0.8-2.0)$ & $1(0.7-2)$ & 0.058 & $2(0.5-2)$ & $1(0.8-2)$ & 0.776 \\
\hline $\begin{array}{l}\text { Time sitting/reclining hrs mean } \\
{\text { (range })^{+}}\end{array}$ & $4(2-6)$ & $4.0(2-6)$ & $4(2-7)$ & 0.004 & $5(2.5-8.0)$ & $4(2-6)$ & 0.001 \\
\hline METS*, median (Q1-Q3) & $\begin{array}{l}10800 \\
(3840-21120)\end{array}$ & $\begin{array}{l}13474 \\
(5040-24960)\end{array}$ & $\begin{array}{l}8400 \\
(3168-15630)\end{array}$ & 0.000 & $\begin{array}{l}11520 \\
(3840-21110)\end{array}$ & $\begin{array}{l}10630 \\
(3840-21120)\end{array}$ & 0.998 \\
\hline
\end{tabular}

${ }^{+}$Hours per day; sleeping time not included; *METs = metabolic equivalent minutes per week; Q1-Q3 = inter-quartile range; SD = standard deviation.

$\dagger \mathrm{P}$ value for sex comparison. $¥ \mathrm{P}$ value for Hypertensive status comparison.

\& DBP females had lower BP reading in the younger age strata and higher reading in the older age strata, with the transition occurring in the 35-44 yr age strata.

Among those subject with screening detected blood pressure, that was higher than JNC defined optimal blood pressure (BP $>120 / 80 \mathrm{mmHg}$ ) (i.e. excluding those with known hypertension and or on treatment), $59.3 \%$ had prehypertension (61.8\% male; $56.6 \%$ females) and $6.2 \%$ had Stage 1 and 4.1\% Stage 2 Hypertension (Table 2).

In the entire sample, the crude prevalence (95\% CI) of Isolated Systolic Hypertension (ISH) and Isolated Diastolic Hypertension (IDH) was 1.6\% (1.1, 2.2); [males 1.5\% $(0.8,2.2)$ females $1.8 \%(1.2,2.7)]$, and $2.7 \%(2.0,3.4)$ [males $2.9 \%(1.9,4.1)$ females $2.5 \%(1.6,3.5)]$ respectively. The combined prevalence of ISH and IDH in the entire sample was $6.0 \%(4.9,7.0) ; 5.9 \%(4.1,7.4)$ in males and $6.1 \%(4.6$, $7.7)$ in females. The age strata of 55-64 yrs. demonstrated a higher female prevalence of high blood pressure and combined systolic and diastolic hypertension (Additional file 1). Additional file 2 depicts the crude prevalence of high blood pressure and isolated forms of hypertension in those with high blood pressure (ie excluding subjects with known hypertension and on treatment at survey).
Risk factors distribution by hypertension status

Behavioural cardiovascular risk factors distribution by hypertensive status are depicted in Table 1. Compared to normotensive, a larger proportion of hypertensive subjects were current Smokers (17.8\%; 12.5\%; P =0.018), had commenced smoking at older age (21.4 yrs.; 15.4 yrs; $\mathrm{P}=0.037)$ and had a longer duration of smoking (8.3 yrs, 6.0 yrs, $\mathrm{P}=0.001$ ). Alcohol consumption levels among hypertensives was high and equal to that of normotensives and the entire sample. Hypertensives demonstrated a similar pattern of high level of physical activity (PA) as normotensives. The median total PA (Q1-Q3)) in METminute per week in hypertensive subjects was 11520 (3840, 21110) and $10630(3840,21120)$ in normotensive subjects $(\mathrm{P}=0.998)$.

Categories of body mass indices stratified on hypertensive status are depicted in Table 3. Compared to normotensive, the age, sex and alcohol adjusted OR (95\% CI) of a hypertensive being obese was $2.9(1.9,4.4)$, of being over-weight $1.8(1.2,2.5)$ and of having waistline defined central obesity $2.4(1.6, .6)$; with no significant gender differences. An elevated waist-hip ratio was not significantly associated with an increased likelihood of hypertension (OR 1.3; 95\% CI 0.8, 2.0). The proportion of hypertensive

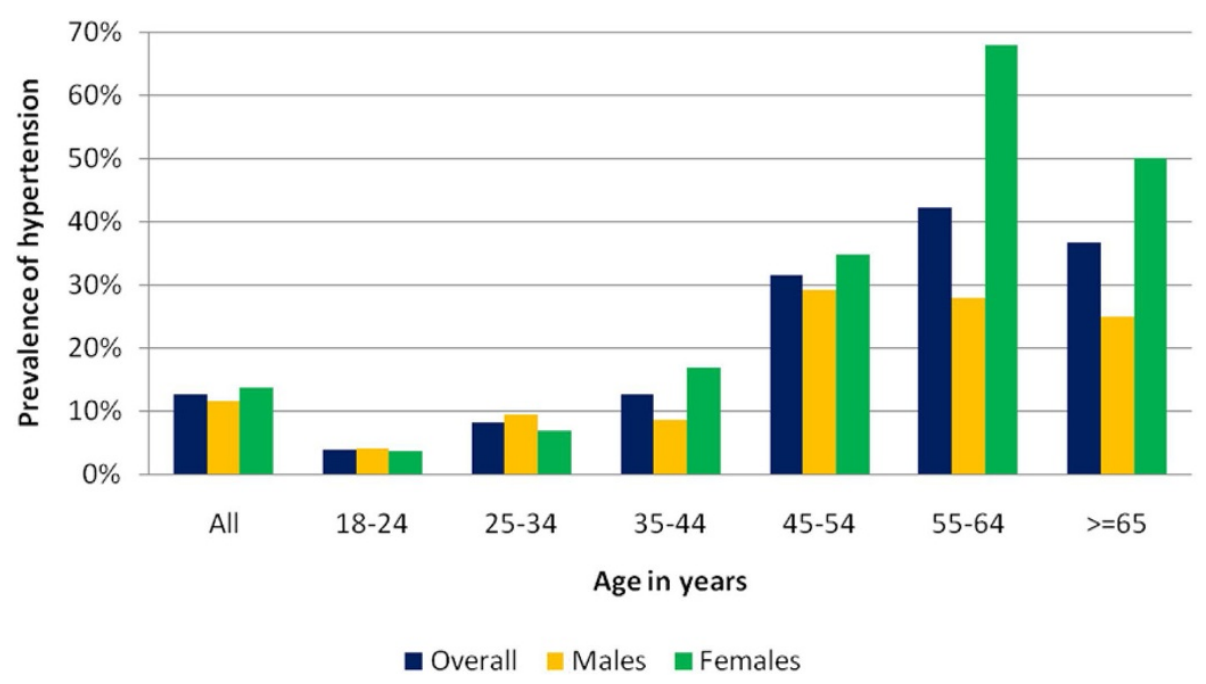

Figure 1 Prevalence of hypertension across age and sex. 
Table 2 Prevalence of hypertension, high blood pressure, pre-hypertension and hypertension stages

\begin{tabular}{lllll}
\hline & $\begin{array}{l}\text { Overall } \\
\mathbf{n}(\%)\end{array}$ & $\begin{array}{l}\text { Male } \\
\mathbf{n}(\%)\end{array}$ & $\begin{array}{l}\text { Female } \\
\mathbf{n}(\%)\end{array}$ & P value \\
\hline $\begin{array}{l}\text { Hypertension } \\
\text { Yes }\end{array}$ & $258(12.6)$ & $122(11.6)$ & $136(13.7)$ & 0.165 \\
No & $1787(87.4)$ & $928(88.4)$ & $859(86.3)$ & \\
Blood Pressure & & & & \\
Normal & $604(30.4)$ & $288(27.9)$ & $316(33.1)$ & 0.073 \\
Pre-Hypertension & $1178(59.3)$ & $637(61.8)$ & $541(56.6)$ & \\
High Blood Pressure* & $205(10.3)$ & $106(10.3)$ & $99(10.4)$ & \\
Stage 1 & $124(6.2)$ & $65(6.3)$ & $59(6.2)$ & \\
Stage 2 & $81(4.1)$ & $41(4.0)$ & $40(4.2)$ & \\
\hline
\end{tabular}

*High Blood Pressure category excludes subjects known to be hypertensive and on treatment at survey.

subjects who also had diabetes was $14 \%$ (n 36). Compared to normotensive, hypertensive subjects were 4.4 -fold ( $95 \%$ CI 2.4-8.3) more likely to have diabetes. The odds of a female hypertensive having diabetes was 2.9 fold (95\% CI $1.0,8.3)$ that of a male hypertensive though this was of borderline statistical significance $(P=0.049)$. The odds of diabetes in the normotensive did not demonstrate a gender propensity.

In a multivariable linear regression model, the association between age and WC with blood pressure (BP) showed that per decade increase in age SBP increased by $2.6 \mathrm{mmHg}$ (1.86 $\mathrm{mmHg}$ males; $3.6 \mathrm{mmHg}$ females) and DBP increased by $2.2 \mathrm{mmHg}(1.6 \mathrm{mmHg}$ males; $3.0 \mathrm{mmHg}$ females).Similarly per five centimetre increase in WC, SBP increased by $0.50 \mathrm{mmHg}(0.78 \mathrm{~mm}$ $\mathrm{Hg}$ males \& $0.35 \mathrm{mmHg}$ females) and DBP increased by $0.40 \mathrm{mmHg}$ (0.56 $\mathrm{mmHg}$ male; $0.32 \mathrm{mmHg}$ females). Per unit increase in BMI, SBP increased by $0.2 \mathrm{mmHg}$ in both gender, and DBP increased by $0.08 \mathrm{mmHg}$ (0.12 mmHg males, $0.06 \mathrm{mmHg}$ females).

\section{Discussion}

This study of adults living in the largest urban slum in Kenya shows high age adjusted prevalence of hypertension with close to quarter (23\%) classified as hypertensive and $60 \%$ as pre-hypertensive. Majority $(80 \%)$ were undetected and only one in three study subjects had ever undergone blood pressure screening suggesting a low overall awareness of hypertension. Hypertension prevalence increased with age and tended to be higher in women in the older age categories. Our reported hypertension prevalence is consistent with that of recently published reports in rural and urban non-slum African studies [19-21]. Studies on the prevalence of hypertension in Kenya are sparse and until recently none had been undertaken among slum residents [8,9,22]. A 2011 report from Old Town Mombasa reports an adjusted prevalence of 32\% [22]. No regional studies have been undertaken among slum dwellers. Two studies in Kenya have reported on hypertension among poor urban slum residents [23,24]. Of these one was among a nonprobability sample of Kibera slum resident and reported an unadjusted hypertension prevalence of $13 \%$ [24]. The other utilised cluster sampling and reported a WHO standardised population prevalence of $18.4 \%$, inclusive of an $80 \%$ screen detection rate [23].

Our study subjects were homogeneous with regards to high levels of travel or work related physical activity and important high levels of harmful alcohol intake. Ten percent were current smokers. Majority of males had a normal body mass measurement, however females showed a high prevalence of excess body mass with one-third being obese or overweight and 40\% having central obesity.

Correlates of hypertension included advancing age, overweight, general and central obesity which were associated with 2-3 fold increased likelihood of hypertension, affirming that these are risk factor for development of primary hypertension in this population. These associations are well established and have been described in SSA [21], and in particular were similarly demonstrated in a recent Nairobi slum survey report [23].

One out of every seven hypertensive was found to be diabetic with an almost five fold likelihood of a hypertensive being diabetic. In a related publication we reported age adjusted diabetes prevalence of $5 \%$, with one in two persons with diabetes being hypertensive and a threefold likelihood of person with diabetes being hypertensive [25]. The association between these cardiovascular NCD risk factors of diabetes and hypertension is well established, and compounds total cardiovascular risk [26]. This finding points to the possibility of using blood pressure measurement as a first step in cardiovascular non-communicable disease screening in community and resource poor settings.

Our findings of high prevalence of predominantly undetected hypertension and pre-hypertension in association with behavioural/physiological risk factors (of alcohol and high body weight and diabetes) in this poor urban slum community, with high levels of physical activity, point to an early social transition of cardiovascular disease in the urban poor and the need for primary and secondary prevention strategies through lifestyle interventions. Furthermore an increased and sustained awareness of the burden of hypertension among the public and health personnel is required. This will assist in the detection, treatment and control of hypertension and associated risk factors.

A detailed study of the dietary practises contributing to excess body weight and salt intake, in a community with limited opportunity for increased physical activity, is paramount and should be undertaken alongside that 
Table 3 Body Mass Indices and Diabetes Distribution by Hypertension Status

\begin{tabular}{|c|c|c|c|c|c|c|c|c|c|c|}
\hline Variable & $\begin{array}{l}\text { Hyper-tensive } \\
\%(\mathrm{n})\end{array}$ & $\begin{array}{l}\text { Normo-tensive } \\
\% \text { (n) }\end{array}$ & $\begin{array}{l}\text { Odds ratio } \\
(95 \% \mathrm{Cl})\end{array}$ & $p$ value & $\begin{array}{l}\text { Age adjusted } \\
\text { odds ratio } \\
\text { (95\% Cl) }\end{array}$ & $p$ value & $\begin{array}{l}\text { Age-sex adjusted } \\
\text { odds ratio }(95 \% \mathrm{Cl})\end{array}$ & $p$ value & $\begin{array}{l}\text { Age-sex-smoking-alcohol } \\
\text { use adjusted odds ratio } \\
(95 \% \mathrm{Cl})\end{array}$ & $p$ value \\
\hline \multicolumn{11}{|c|}{ BMI $(n=2037)$} \\
\hline$\geq 30$ & $34.0(87)$ & $13.8(245)$ & $4.4(3.1-6.2)$ & 0.000 & $3.2(2.3-4.6)$ & 0.000 & $3.2(2.2-4.7)$ & 0.000 & $2.9(1.9-4.4)$ & 0.000 \\
\hline$>25-29.9$ & $33.6(86)$ & $28.4(506)$ & $2.1(1.5-2.9)$ & 0.000 & $1.7(1.2-2.4)$ & 0.002 & $1.7(1.2-2.4)$ & 0.002 & $1.8(1.2-2.5)$ & 0.003 \\
\hline $18.5-25$ & $29.7(76)$ & $53.0(943)$ & Ref & & Ref & & Ref & & Ref & \\
\hline$<18.5$ & $2.7(7)$ & $4.8(85)$ & $1.0(0.5-2.3)$ & 0.956 & $1.1(0.5-2.4)$ & 0.883 & $1.1(0.5-2.4)$ & 0.884 & $1.2(0.5-2.7)$ & 0.745 \\
\hline \multicolumn{11}{|c|}{ Waist Circ. $(n=2032)$} \\
\hline Elevated & $39.6(101)$ & $18.9(335)$ & $2.8(2.1-3.7)$ & 0.000 & $2.1(1.6-2.8)$ & 0.000 & $2.4(1.6-3.5)$ & 0.000 & $2.4(1.6-3.6)$ & 0.000 \\
\hline Normal & $60.4(154)$ & $81.1(1440)$ & Ref & & Ref & & Ref & & Ref & \\
\hline \multicolumn{11}{|c|}{ Waist Hip Ratio (n 2027) } \\
\hline High & $22.0(56)$ & $12.0(212)$ & $2.1(1.5-2.9)$ & 0.000 & $1.6(1.1-2.2)$ & 0.012 & $1.4(1.0-2.1)$ & 0.074 & $1.3(0.8-2.0)$ & 0.273 \\
\hline Normal & $78.0(198)$ & $88.0(1559)$ & Ref & & Ref & & Ref & & Ref & \\
\hline Diabetes & $14.0(36)$ & $1.7(30)$ & $9.5(5.7-15.7)$ & 0.000 & $5.1(3.0-8.7)$ & 0.000 & $4.9(2.9-8.5)$ & 0.000 & $4.4(2.4-8.3)$ & 0.000 \\
\hline No Diabetes & 86.0 (222) & 98.3 (1758) & Ref & & Ref & & Ref & & Ref & \\
\hline
\end{tabular}

$\mathrm{BMI}=$ body mass index. Categories: $\geq 30$ Obese; $>25-29.9$ Over-weight $<18.5$ Under-weight.

Waist Circ = Waist Circumference. Categories: Elevated Male $>102 \mathrm{~cm}$; Female $>88 \mathrm{~cm}$.

Waist Hip Ratio High: $>0.90$ males and 0.80 in females. 
of the culturally acceptable and desired body shapes among Africans. This in particular among females who have a greater burden of obesity and have been shown in other studies to have a lack of awareness of the presence and hazards of excess body weight and thus little desire for change [27].

\section{Strengths and limitations}

To the best of our knowledge this is among the first published urban slum NCD survey report from Kenya, whose strengths and limitations have been discussed in a related publication. [25]. In brief our strengths include reported age standardised prevalence, utilising standard survey methods that allow for comparability across studies and regions. By sampling an average of 2.4 adults per household we do not expect that over representation of family size impacted our results. We acknowledge the random walk method in household survey as not optimal for obtaining a probabilistic sample. The availability of dietary data, including salt intake, and socioeconomic and lipid profile data would have strengthened our findings. The limitations of self reported physical activity and the inherent limitation of a cross-sectional study design in prohibiting causal interpretation are acknowledged. Our instruments standardisation method for weight and BP, were suited to a field slum study circumstances, however could have potentially introduced a non-differential bias. In clinical practice, a diagnosis of hypertension requires multiple measurements on several occasions. We took a single occasion measurement and therefore, the prevalence of hypertension found in our survey may represent an overestimation.

\section{Conclusion}

In conclusion the age adjusted prevalence of hypertension is high, even among the urban poor living in a low income country, and is significantly correlated with overweight and obesity that is not uncommon among this community. Majority of the hypertensive subjects are undetected and therefore unaware of the risks they face; a recognised major impediment to control of hypertension. This points to the need for greater awareness of hypertension in the general population and health care givers. In tandem, within the health system greater emphasis needs to be placed on detection, treatment and control of high blood pressure. Preventive efforts targeting behavioural lifestyle changes, at community level, to curtail these risk factors at population and individual level is urgently required. Reducing these risk factors will not only have an effect on hypertension, but will also have wide-reaching beneficial effects for other chronic non-communicable diseases.

\section{Additional files}

\section{Additional file 1: Prevalence of high blood pressure and isolated} forms of hypertension by age and sex.

Additional file 2: Prevalence of high blood pressure and isolated forms of hypertension in those with high blood pressure by age and sex.

Competing interests

The authors declare that they have no competing interests.

\section{Authors' contributions}

MDJ conceived the study, participated in the design of the study, performed the statistical analysis and drafted the manuscript. RA conceived of the study participated in the design, performed the statistical analysis and drafted the manuscript. EKN conceived of the study, participated in the design performed the statistical analysis and helped draft the manuscript. RW conceived of the study, participated in the design performed the statistical analysis and helped draft the manuscript. EKN participated in the design of the study and performed the statistical analysis. JKK participated in the design and helped draft the manuscript. KKM performed the statistical analysis and helped draft the manuscript. All authors read and approved the final manuscript.

\section{Acknowledgements}

The authors would like to acknowledge the study participants and the survey team. The study did not receive any external funding.

\section{Author details}

${ }^{1}$ Department of Clinical Medicine and Therapeutics, School of Medicine, College of Health Sciences, University of Nairobi, P.O. BOX 19676-00202, KNH, Nairobi, Kenya. ${ }^{2}$ School of Public Health, College of Health Sciences, University of Nairobi, Nairobi, Kenya. ${ }^{3}$ University of Nairobi Partnership for Advanced Care and Treatment (PACT) - Centre of Excellence, Nairobi, Kenya.

Received: 27 February 2014 Accepted: 24 October 2014

Published: 18 November 2014

\section{References}

1. World Health Organization: Global Status Report on Noncommunicable Diseases: 2010. Geneva: World Health Organization; 2011.

2. Jamison DT, Breman JG, Measham AR, Alleyne G, Claeson M, Evans DB, Jha P, Mills A, Musgrove P (Eds): Disease Control Priorities in Developing Countries. 2nd edition. Washington (DC): World Bank; 2006.

3. Kearney PM, Whelton M, Reynolds K, Whelton PK, He J: Worldwide prevalence of hypertension: a systematic review. J Hypertens 2004, 22:11-19.

4. Whelton PK, Brancati FC, Appel $L J$, Klag MJ: The challenge of hypertension and atherosclerotic cardiovascular disease in economically developing countries. High Blood Press 1995, 4:36-45.

5. Brundtland GH: The World Health Report 2002: Reducing Risks, Promoting Healthy Life. Geneva: World Health Organization; 2002.

6. WHO: WHO Regional Office for Africa Cardiovascular Diseases in the African region afr/rc55/12 17 June 2005; Available from http://apps.who.int/iris/bitstream/10665/ 1871/1/AFR\%20RC55-12.pdf?ua=1. Accessed 20th November 2014.

7. Walker RW, McLarty DG, Kitange HM, Whiting D, Masuki G, Mtasiwa DM, Machibya H, Unwin N, Alberti KGMM: Stroke mortality in urban and rural Tanzania. Lancet 2000, 355:1684-1687.

8. Katsivo MN, Apeagye: Hypertension in Kitui District: a comparative study between urban and rural populations. East Afr Med J 1991, 68:531-537.

9. Mathenge W, Foster A, Kuper H: Urbanization, ethnicity and cardiovascular risk in a population in transition in Nakuru, Kenya: a population based survey. BMC Public Health 2010, 10:569-581.

10. Yusuf S, Reddy S, Ounpuu S, Anand S: Global burden of cardiovascular diseases. Part I: general considerations, the epidemiologic transition, risk factors, and impact of urbanization. Circulation 2001, 104:2746-2753.

11. Kenya National Bureau of Statistics (KNBS): Kenya Population and Housing Census. Nairobi: Kenya National Bureau of Statistics; 2009.

12. Department of Economics and Social Affairs United Nations: Designing Household Survey Samples: Practical Guidelines (Series F) No.98. United 
Nations. Statistics Division, Ed. New York: United Nations, Department of Economic and Social Affairs; 2008.

13. World Health Organization (WHO): STEP Wise Approach to Surveillance (STEPS). Available from: URL: http://www.who.int/chp/steps/en/ (accessed May 1 2010).

14. NHLBI Obesity Education Initiative Expert Panel on the Identification: Clinical Guidelines on the Identification, Evaluation, and Treatment of Overweight and Obesity in Adults. National Heart, Lung, and Blood Institute; 1998.

15. Pickering TG, Hall JE, Appel LJ, Falkner BE, Graves J, Hill MN, Jones DW, Kurtz T, Sheps SG, Roccella EJ: Recommendations for blood pressure measurement in humans and experimental animals part 1: blood pressure measurement in humans. Hypertension 2005, 45:142-161.

16. Chobanian AV, Bakris GL, Black HR, Cushman WC, Green LA, Izzo JL Jr, Jones DW, Materson BJ, Oparil S, Wright JT, Rocella E: National High Blood Pressure Education Program Coordinating Committee. Seventh report of the Joint National Committee on Prevention, Detection, Evaluation, and Treatment of High Blood Pressure. Hypertension 2003, 42:1206-1252.

17. Global Physical Activity Analysis Guide: GPAQ Analysis Guide. Accessed 2nd Jan 2014. Available at www.who.int/chp/steps.

18. Ahmad OB, Boschi-Pinto C, Lopez AD, Murray CJL, Lozano R, Inoue M: Age Standardisation of Rates: a New WHO Standard. Global Program on Evidence for Health Policy Discussion Paper Series: No 31. Geneva: World Health Organisation; 2001.

19. Addo J, Smeeth L, Da Leon: Hypertension in sub-Saharan Africa: a systematic review. Hypertension 2007, 50:1012-1018.

20. Dzudie A, Kengne AP, Muna WF, Ba H, Menanga A, Kouam KC, Abah J, Monkam Y, Biholong C, Mintom P, Kamdem F, Djomo A, Ndjebet J, Wambo C, Luma H, Ngu KB, Kinque S: Prevalence, awareness, treatment and control of hypertension in a self-selected sub-Saharan African urban population: a cross-sectional study. BMJ Open 2012, 2. doi:10.1136/ bmjopen-2012-001217.

21. Hendriks ME, Wit FWNM, Roos MTL, Brewster LM, Akande TM, de Beerl $H_{1}$ Mfinanga SG, Kahwa AM, Gatongi P, VanRooy G, Janssens W, Lammers J, Kramer B, Bonfrer I, Gaeb E, van der Gaag J, deWit TFR, Lange JMA, Schultz C: Hypertension in Sub-Saharan Africa: cross-sectional surveys in four rural and urban communities. PLOS ONE 2012, 7(3):e32638. doi:10.1371/ journal.pone.0032638.

22. Jenson A, Omar AL, Omar MA, Rishad AS, Khoshnood K: Assessment of hypertension control in a district of Mombasa, Kenya. Glob Public Health 2011, 6:293-306.

23. van de Vijver SJ, Oti SO, Agyemang C, Gomez GB, Kyobutungi C: Prevalence, awareness, treatment and control of hypertension among slum dwellers in Nairobi, Kenya. J Hypertens 2013, 31:1018-1024.

24. Ongeti KW, Ogengo JA, Pulei AN, Olabu BO, Gakara CN: Blood pressure characteristics among slum dwellers in Kenya. Glob Adv Res J Microbiol 2013, 2:080-085.

25. Ayah R, Joshi MD, Wanjiru R, Njau EN, Otieno CF, Njeru EK, Mutai K: A population-based survey of prevalence of diabetes and correlates in an urban slum community in Nairobi, Kenya. BMC Public Health 2013, 13:371.

26. le Ferrannini E, Cushma WC: Diabetes and hypertension: the bad companions. Lancet 2012, 380:601-610.

27. Njelekela MA, Mpembeni R, Muhihi A, Mligiliche NL, Spiegelman D, Hertzmark E, Liu E, Finkelstein JL, Fawzi WW, Willett WC, Mtabaji J: Gender-related differences in the prevalence of cardiovascular disease risk factors and their correlates in urban Tanzania. BMC Cardiovasc Disord 2009, 9:30

doi:10.1186/1471-2458-14-1177

Cite this article as: Joshi et al:: Prevalence of hypertension and associated cardiovascular risk factors in an urban slum in Nairobi, Kenya: A population-based survey. BMC Public Health 2014 14:1177.

\section{Submit your next manuscript to BioMed Central and take full advantage of:}

- Convenient online submission

- Thorough peer review

- No space constraints or color figure charges

- Immediate publication on acceptance

- Inclusion in PubMed, CAS, Scopus and Google Scholar

- Research which is freely available for redistribution

Submit your manuscript at www.biomedcentral.com/submit
Ciomed Central 